\title{
Polisemia
}

\section{PENSAR Y ACTUAR LA PAZ: GIRO EPISTEMOLÓGICO Y GIRO PRAXEOLÓGICO}

Clara Stella Juliao Vargas ${ }^{1}$

\section{Resumen}

$\mathrm{E}$ n primera instancia, este artículo pretende resaltar algunos de los conceptos relacionados con el tema de la paz-como son la complejidad, la socialización, el conflicto, las buenas prácticas de paz, el empoderamiento pacifista, la resistencia civil, la paz imperfecta, la no-violencia-, buscando relacionarlos entre sí, para demostrar que es esencial hacer no sólo un giro epistemológico sino lo que podría llamar un giro praxeológico.

Mencionamos situaciones de las comunidades de paz, en el marco de la zonas humanitarias en Colombia, para mostrarlas como ejemplos de autodeterminación de poblaciones que no por ser frágiles pueden ser consideradas víctimas, sino como potencia de cambio por haber escogido una forma alternativa para vivir y a pesar de encontrarse en medio del conflicto entre otros agentes, como ellos mismos lo declaran. En consecuencia, merecen que su situación sea distinguida dentro del tema del empoderamiento pacifista.

Todo esto, con el ánimo de aclarar que nuestro reto como estudiosos de la paz no es sólo pensar en ella sino también actuar en busca de la paz.

\section{Palabras Claves}

Praxeología, conflicto, prácticas de paz, empoderamiento pacifista, resistencia civil, paz imperfecta, no-violencia

\section{THINKING ABOUT PEACE AND ACTING PEACE: PRAXEOLOGICAL AND EPISTEMOLOGICAL TURN}

\section{Abstract}

This work emphasizes concepts related to peace (including socialization, conflict, good peace's practices, empowerment peaceful, civil resistance, imperfect peace and nonviolence), it relates among them and it shows the importance of both epistemological and praxeological turn in their approach.

The author gives examples about the peace communities in the framework of the humanitarianzones in Colombia. Sheshows them likesituationsofself-determination 
of the populations which should be seen as a pacific power due to they have chosen a peaceful alternative to live despite of being in the middle of conflict between other agents.

\section{Key Words}

Praxeology, conflict, peace practices, peaceful empowerment, civil resistance, imperfect peace, nonviolence

Pensar la paz y aún más, actuar la paz, es un reto; desde cualquier perspectiva o ángulo que se mire, siempre habrá mucho que decir y mucho que hacer.

\section{PENSAR Y ACTUAR LA PAZ: GIRO EPISTEMOLÓGICO Y GIRO PRAXEOLÓGICO}

Mucho que decir, porque hay y habrá tanta diversidad de opiniones y visiones como estudiosos o interesados en el tema, aunque tengan puntos de encuentro y acuerdo entre ellos.

Mucho que hacer, porque las condiciones de paz, las situaciones de pazy los momentos de paz vienen y van, igual que los de violencia, a veces sin que los mismos actores implicados se den cuenta inmediata de los cambios y movimientos, que se van generando en los individuos, en sus relaciones, en su entorno y en las relaciones de aquellos con este.

La última idea nos aproxima al tema de la complejidad en la que se sumergen, no sólo el ser humano, sino los demás seres vivos, la naturaleza, todo lo que les rodea. ${ }^{2}$ Complejidad ligada a la incertidumbre de lo no acabado, de lo imperfecto ${ }^{3}$, de lo que esta en evolución permanente y frente a lo cual aún podemos pensar y tomar acción, situación que nos humaniza y hace posible que no nos conformemos con situaciones que no correspondan a lo que queremos y ansiamos como bienestar y armonía. ${ }^{4}$

Las entidades humanas (personas, grupos, especie) no surgieron perfectas, han evolucionado y aún no han concluido su proceso; no todas van en la misma línea, ni están en el mismo punto de dicho proceso. Las estructuras y la organización que median las relaciones entre los seres humanos y entre estos y el universo, no son iguales y esas desigualdades generan tensión, conflicto, muchas veces expresados en forma violenta y otras tantas mediadas por expresiones pacifistas, reconciliadoras, no-violentas, dependiendo de las experiencias previas y del aprendizaje que se haya tenido. ${ }^{5}$

En este momento es oportuno resaltar otro tema ligado a las experiencias previas y al aprendizaje de las prácticas pacifistas o violentas: el tema de la socialización. La humanidad ha creado su historia, la ha compartido de generación en generación, ha reproducido formas de pensar y actuar, formas de organizarse y de responder a los cambios. Adaptándose a ellos de una u otra manera, cada grupo humano o individuo, si se prefiere, tiene su concepción global del mundo, la cual puede estar más cerca o más lejos de la realidad. ${ }^{6}$ Por eso mismo, el ser humano ha aprendido su forma de actuar y pensar de otros seres humanos, en el seno de la familia o en otras instancias relacionales, lo que indica que puede aprender otras formas de hacerlo, educándose -como diría Mario López ${ }^{7}$ - poniendo otros valores en el centro. Valores que, en el marco de la educación

2. Muñoz, F. y Molina, B. (2009) "Una paz compleja, conflictiva e inacabada", Instituto de Pazy Conflictos, Univ. de Granada. Ponencia aún no publicada del Seminario Una paz compleja y conflictiva.

3. Muñoz-Herrera-Molina-Sanchez. (2005)"Investigación de la paz y los derechos humanos desde Andalucía", Granada, Colección Monográfica Eirene No. 20.

4. Muñoz, Francisco. (2007) "La paz imperfecta ante un universo en conflicto" apartes 5.2 y 5.3 Granada: Universidad de Granada

5. Muñoz y Molina, (2005) Op. cit, p. 19.

6. Barreix y Castillejos (2003) Metodología y método en trabajo social Buenos Aires: Editorial Espacio, p. 154.

7. Lopez, M. (2006) Política sin violencia, Bogotá: Uniminuto, p. 72. 
del futuro y siguiendo a Moran, ${ }^{8}$ deben reconocer la diversidad cultural ligada a la condición humana y sus posibilidades de transformación. Así mismo, recordar lo dicho por Arias $^{9}$ sobre lo difícil que puede ser transformar la no-violencia mediante una conferencia o un libro, indicando que sí se podría cambiar con el ejemplo, sobre todo con el ejemplo de muchos y decididos no violentos. En últimas, quiero indicar, se haría fácil con nuestro ejemplo, con nuestro actuar, con nuestra praxis no-violenta. Una práctica de no-violencia conocida y reconocida incita a prácticas similares. No sólo hay que cambiar nuestra forma de pensar y actuar frente al conflicto, sino que, en los diferentes frentes de nuestra vida, como profesionales, como ciudadanos o ciudadanas, como directivos, docentes $\mathrm{o}$ estudiantes y especialmente como miembros de nuestra familia, debemos mostrar como práctica cotidiana, nuestra creencia y actuación no-violenta.

Aprendimos muchas cosas, por ejemplo, de la propia relación con la naturaleza, que nos hacen diferentes unos de otros, en palabras de Galtung:"Una vez más, las implicaciones son evidentes: Occidente recibe preparación para el comportamiento agresivo hacia otros seres humanos a través de su comportamiento hacia los animales y otras formas de la naturaleza; los orientales reciben su preparación en sentido opuesto". ${ }^{10}$

En este caso el análisis no implica quedarnos en lo que aprendimos, en lo que nos enseñaron, en lo que siempre hemos visto y entendido, resaltando lo acostumbrado, es decir lo violento del conflicto, lo negativo de las situaciones y agentes que en él se enfrentan, quedarnos en el paradigma de la paz negativa, ${ }^{11}$ y por lo mismo la tendencia a negar y/o rechazar el conflicto por estar asociado a violencia; por el contrario, se refiere a transformación del conflicto a partir de la aceptación del mismo y la cooperación como "dos caras de la misma moneda de las relaciones humanas", 12 lo cual implica cambiar de percepción, renovar la mirada con un nuevo paradigma que deje de pensar en la guerra y en el enfrentamiento agresivo y violento, para reconocer las capacidades del ser humano, trasformar y gestionar los conflictos en forma pacífica. Se trata de ver al ser humano en su grandeza y de allí la posibilidad de resolver las dificultades y contradicciones cotidianas pacíficamente, sin necesidad de oponerse al otro como agresor, sino más bien como otra versión de sí mismo con probabilidad de compartir intereses y objetivos, a pesar de que inicialmente no lo parezca.

Ahora bien, el ser humano puede pensar no solo lo mismo que piensan otros o sobre lo que actúan otros. Sería interesante caer y creer, en la posibilidad de que todo ser humano imaginara sobre su actuar frente a la paz, aprendiera de su propia reflexión, sobre su propia práctica (praxeología) de paz; y que mientras analiza y reflexiona sobre lo que ha sido y es el conflicto, pudiera también revisar sus propias acciones frente al tema, sus reacciones, emociones y comportamientos, frente a situaciones que le afectan, le generan malestar y ponen en peligro su integridad, su dignidad humana o sus valores. En otros términos, valdría la pena que a partir de la cavilación sobre su propio actuar y pensar, se plantee nuevas formas de hacerlo, procese para sí mismo y para ejemplo de otros un giro praxiológico, si determina que su actuar hasta ahora no ha contribuido a generar cultura de paz y no violencia.

8.Moran, E. (1999) "Los siete saberes necesarios para la educación del futuro", Bogotá: Edit. Magisterio.

9. Arias, G. (1995) Proyecto político de la no-violencia, Madrid: Nueva utopía, p. 10

10. Galtung, J. (1995) Investigaciones teóricas: sociedad y cultura contemporánea Madrid: Tecnos, p. 37.

11. Martínez Guzmán, V. (2004): Teorías de la guerra en el contexto político de comienzos del siglo XXI, en Murillo, I. (ed.) (2004): Filosofía práctica y persona humana, Salamanca, Servicio de Publicaciones Universidad Pontificia de Salamanca, Salamanca: Ediciones Diálogo Filosófico.

12. Martínez Guzmán, V. (2000 - septiembre) "Saber hacer las Paces. Epistemologías de los estudios para la paz" en Convergencia, Revista de ciencias sociales, Universidad Autónoma de México, Numero 23 p. 77. 
Ahora bien, gracias a la educación cada ser humano genera su concepción del mundo, escoge y decide el rol que asumirá frente a él; de alguna forma construye los ideales y las apreciaciones mediante los cuales orienta su actividad, su compromiso histórico ${ }^{13}$ y por lo mismo su enfoque y orientación al actuar.

Compromiso que se relaciona, según Martínez Guzmán, ${ }^{14}$ con la comunicación que establece con otras entidades humanas, al expresar su sentir y su pensar, generando lazos e interacción como expresión de la solidaridad y la confianza mutua que esta implica.

Lo anterior, lógicamente ligado a lo que Muñoz y Molina ${ }^{15}$ mencionaron como la capacidad de abstracción y comprensión humana, que le permite al ser humano "asimilar y reproducir actitudes y conductas de éxito en escenarios diferentes", al referirse a la regulación pacífica de un conflicto, en el marco de la "elección", dentro de la complejidad de matices y circunstancias en las que se abre paso el concepto de paz imperfecta, como proceso que permite visualizarhorizontes más justos, que indiquen una construcción basada en la regulación pacífica del conflicto, en el reconocimiento de lo inacabado, la posibilidad de lograr mejores condiciones de bienestar para la humanidad y lógicamente, aprender no sólo teoría de no-violencia sino su acción y su forma de hacer política.

En este marco, la no-violencia como práctica sociopolítica -sus estrategias y procedimientos de lucha: forcejeo y presión político social- ha sido utilizada en muchos casos por los grupos de población que ven afectados sus derechos o que han querido evidenciar situaciones de injusticia contra ellos o contra sus congéneres.

Esto me lleva a indicar que la no-violencia está basada en un comportamiento ético, consciente, intencionado y responsable, que supera los parámetros legales de los métodos democráticos, se apoya en un cambio de mentalidad, de la manera de gestionar los conflictos, en reconocer que la acción y la presión política se pueden hacer sin violencia, pero que admite y resalta las posibles injusticias e inequidades que se presentan aún en los procesos democráticos, los cuales tienden a preservar el estado de cosas, aunque muchas veces sean injustas para algunos grupos de población.

También podría decir que a simple vista métodos democráticos como los propuestos por la no-violencia son similares, pues ambos hablan de desarrollar consensos, negociación, no imposición, pacto, acuerdo, entendimiento, persuasión, toma de decisiones compartidas, transparencia, etc, Sin embargo, tienen grandes diferencias en cuanto a su alcance y enfoque orientador, pues para la democracia juega un papel importante (es decir, pesa más) la representación y la mayoría aunque no se llegue al consenso.

Además, en la democracia no siempre se procede bajo el llamado juego limpio, siendo escrupulosos en el establecimiento de las formas y las reglas que brinden igualdad para todos y que realmente promuevan la participación de la mayoría. En muchos casos la información y formación no alcanza a toda la población, entonces, en las discusiones y la toma de decisiones hay escasa presencia de la ciudadanía. Por ejemplo, para las decisiones de inversión social en una ciudad como Bogotá, se definieron por ley los encuentros ciudadanos, para escuchar "la voz de los y las ciudadanas" y contar con su participación al seleccionar los proyectos en los cuales se podrían invertir, pero se olvidaron de un detalle: según los plazos dados, quienes asistirían carecían del suficiente tiempo para haberse organizado previamente en torno a una información

13. García Carrasco, citado por Juliao, C. (2007) Educación Social: el Minuto de Dios una experiencia y un modelo, Bogotá: Uniminuto, p. 11.

14. Martínez Guzmán, V. (2000) Op. Cit.p. 36.

15. Muñozy Molina, Op. Cit., p. 19 y 21. 
completa, por tanto, fueron a escuchar, pero no lograban llegar a consensos, pues sólo conocían su propio proyecto y no los de sus conciudadanos, tampoco conocían las necesidades ni prioridades, además, ni el tiempo de debate ni el de reflexión fue suficiente. Por lo tanto dichos encuentros se han convertido en sesiones de presentación política y clientelismo en torno a las prioridades y proyectos que ya han sido, o serán, definidos en otros espacios.

En este caso podría pensarse en acciones no violentas que contrarrestaran el uso impropio de esta herramienta que de fortalecerse podría ser valiosa, pero aún no ha sido utilizada adecuadamente. Por ejemplo, un grupo organizado en una localidad, al menos podría plantearse la posibilidad de obstaculizar dichos encuentros mientras no existan condiciones previas de información y organización. Podría definir no asistir, o asistir y no entrar al recinto, manifestando su inconformidad con condiciones previas, como la falta de información, que dificultan su participación activa.

De igual forma al hablar de democracia, se habla y admite el pluralismo político y la tolerancia, como prácticas y valores, pero no se defienden ni respetan en todos los momentos, llegando a ser permisivos con situaciones que atentan contra el mencionado juego limpio, aunque se esté hablando de transparencia y rendición de cuentas.

Aclaremos que por su parte, la no-violencia no es sólo teoría, sino también investigaciónacción, es la aplicación concreta de lo que se piensa. "La no-violencia es una forma de práctica sociopolítica, todo un conjunto de estrategias y procedimientos de lucha, forcejeo y presión político social. Así como una doctrina de los cambios sociales". ${ }^{16}$

Sin embargo, en esas relaciones entre los seres

humanos, existen circunstancias mediadas por la capacidad de confiar en el otro. Para el caso de Colombia, retomo los resultados de un estudio relacionado con el capital social ${ }^{17}$, el cual, sin ser concluyente, resalta que cerca de la mitad de los colombianos no participa en ninguna organización voluntaria laica, y sólo $9 \%$ manifiesta que confía en otras personas. Vale la pena mencionar cómo ese porcentaje de confianza es más notable en los sectores rurales: sectores de indígenas, campesinos y afro colombianos donde por razones de parentesco o de amistad, la población confía y coopera con otros en procesos individuales o colectivos. Vale citar como ejemplo el caso de las zonas humanitarias y comunidades de paz que surgen como una estrategia de protección en medio del conflicto armado que vive el país. Estas zonas humanitarias, como enclaves de resistencia civil han permitido que las comunidades se agrupen, se organicen, y emprendan proyectos de vida autónomos apoyados por el Derecho Humanitario Internacional, además de la compañía de ONGs nacionales e internacionales y algunos estamentos eclesiásticos.

\section{Tengamos en cuenta que:}

Una Zona humanitaria es un mecanismo de concreción del Derecho Internacional Humanitario, que posibilita la distinción territorial de pobladores civiles de los combatientes por ser un espacio perfectamente visibilizado, de propiedad comunitaria-familiar, en el que sehabita yse trabaja-siembras depan cogeren su interior o su entorno, se estudia el desarrollo de propuestas de etno-educación, se previenen el desplazamiento forzado y las violaciones de derechos humanos-, que se ubica en lugares que no son estratégicos en los modelos de guerra estatal ni guerrillero, que es reconocido por la Corte Interamericana de Derechos Humanos. ${ }^{18}$ 
Y que las Comunidades de paz son:

Iniciativas de paz desde la base, en construcción, que encuentran su origen en regiones de alta violencia $y$ en comunidades que en medio del fuego cruzado se organizan como expresión de resistencia civil no violenta al conflicto interno armado, dentro de un territorio delimitado que declaran al margen de las hostilidades, para autoprotegerse reivindicando la autonomía e inmunidad de la población civil frente al conflicto armado, reconstruir el tejido social, desarrollar un proyecto de vida soportado en la solidaridad y el bien común, y materializar su derecho a la paz. ${ }^{19}$

Ejemplos de estas zonas son las existentes en los departamentos del Chocó y de Antioquia al occidente colombiano, en el departamento del Meta al oriente del país. Allí, después del desplazamiento forzado, las familias deciden volver a establecerse en zonas cercanas a su hábitat inicial. A partir de la cooperación entre sus miembros y de un largo proceso de no enfrentamiento con los grupos armados se dan a conocer y delimitan una zona humanitaria declarándose comunidad de paz.

Civipaz, comunidad de 17 familias de campesinos desplazados de la región del Alto Ariari, como ejemplo de buena practica, ${ }^{20}$ decidió organizarse en un proceso civil bajo el nombre de Comunidad Civil de Vida y Paz y se estableció en el Corregimiento de Medellín del Ariari, del municipio de El Castillo, departamento del Meta, para reconstruir espacios de habitación y delimitación.

A pesar del control poblacional, del bloqueo económico, hombres, mujeres, jóvenes, niños y niñas, ancianos tomaron la decisión de seguir abriendo ese espacio de libertad. Fueron seis días de trabajo en la tierra, de soñar despiertos, de ver hacer realidad de a poco esos sueños, de encontrarse con los viejos amigos, los otros campesinos que resisten en su tierra. ${ }^{21}$

Por ahora, la esperanza, la alegría del trabajo realizado hasta el momento, la convicción que el retorno sigue siendo la meta, la posibilidad real de protección de tierras ante la negativa del Gobierno de aplicar el Decreto 2007. Por ahora esperar a que el Estado colombiano muestre algo de voluntad política, siquiera para realizar una reunión donde se puedan dejar por escrito compromisos claros frente a este retorno al Alto Ariari. ${ }^{22}$

Las familias de esta comunidad han declarado y dan a conocer su decálogo de vida en cada una de las vallas que delimitan la zona humanitaria, ${ }^{23}$ en él incluyen la verdad, la justicia, la solidaridad, la comunidad, el trabajo, la esperanza, la libertad, la dignidad, la organización y la responsabilidad.

Este tipo de acciones - por ejemplo, las de las comunidades de paz, o las manifestaciones pacificas en contra de la violencia-, son consideradas por algunos como amenaza, porque denuncian acciones y agentes participantes en los hechos, ante organismos nacionales e internacionales de derechos humanos. Para otros -como los campesinos de las veredas, para los habitantes de las ciudades que conocen o conviven con hechos violentos y para los estudiosos de la no violencia-, son signos de esperanza porque aunque continué la presencia de los agentes violentos (comúnmente llamados "victimarios"), los bloqueos económicos a la zona han disminuido, el conocimiento internacional de los hechos ha aumentado y existen organizaciones que apoyan la generación de estrategias y actos que disminuyan la violencia. Por su parte, los miembros de las comunidades de paz, son conscientes de la necesidad de continuar

19. Hernández Delgado, E. (Diciembre-2000) "Comunidades de paz: Expresiones de construcción de paz en medio de la guerray la esperanza" Revista Reflexión Política, Universidad Autónoma de Bucaramanga, Año 2, Núm. 4, P. 32

20. Buena práctica en el sentido del PNUD, se define como aquella "acción o ejemplo concreto que ayuda a disminuir los efectos del conflicto y sentar las bases para una paz sólida y estable" citado por Ricardo León Cruz El Mundo - Septiembre 13 de 2006 en su articulo "Buscar paz : una buena practica", [en línea], disponible en http://indh.pnud.org.co/articulos.plx?t=informePrensa

21. Comision Inter-eclesial de Justicia y Paz, Bogotá, D. C Diciembre 16 de 2005, http://209.85.135.104/search?q=cache:G_ YSdW5y0awJ:es.geocities.com/cijpdever/dv230.doc+\%22Zona+humanitaria\%22\&hl=es\&ct=clnk\&cd=1\&gl=es\&lr=lang_es

22. Comision Inter-eclesial de Justicia y Paz, Bogotá, D. C Diciembre 16 de 2005, http://209.85.135.104/search?q=cache:G_ YSdW5y0awJ:es.geocities.com/cijpdever/dv230.doc+\%22Zona+humanitaria\%22\&hl=es\&ct=clnk\&cd=1\&gl=es\&lr=lang_es 
preparándose para resistir en medio de la guerra y aportar alternativas de paz, empoderándose pacíficamente y dando a conocer sus principios.

Creo importante mencionar que la visión de la acción y la experiencia de comunidades de paz, sigue siendo analizada y mostrada por muchas instancias que los acompañan, especialmente periodistas o investigadores noticiosos que dan a conocer al mundo su situación y ubicación (a los cuales tiene acceso la mayoría de la población en cada país), desde el punto de vista de la guerra, del conflicto, del sufrimiento de la población, del proceso de desplazamiento y de las dificultades y enfrentamientos a que se ven sometidos por el proceso de retorno. En cada uno de los escritos y de las presentaciones que dan a conocer la situación, se resaltan los aspectos de la guerra y la violencia que vivieron o están viviendo, pero sólo en algunos se mencionan los esfuerzos pacifistas y los esfuerzos no-violentos de la comunidad; en la mayoría quedan entre líneas, implícitos si se quiere, estos aspectos esenciales del empoderamiento pacifista de estas poblaciones.

Vale la pena aclarar que en ningún momento se quiere indicar que tales hechos no sean importantes, pues sí lo son, en la medida que atentan contra la dignidad y la vida de la población que está en medio de ellos. Lo que sí se quiere resaltar es la necesidad de utilizar sólo como aclaración o explicación de una situación o de un proceso, no como mecanismo para hacer llamativa dicha situación o como si fuera lo único importante de ella.

Subrayo por tanto, que al ver diferentes documentos dados a la luz pública y en medios masivos sobre los hechos y las vivencias, no es fácil pensar en el giro epistemológico esperado para releer situaciones de paz, ya que pocas veces se muestran procesos no violentos, no se ven desde las acciones o las convicciones de la población que los propone y los asume, sino desde los agentes que se les enfrentan en forma violenta. Esto quiere decir, que no se vislumbra como mecanismo para resolver el conflicto, pues se mira desde la debilidad e impotencia del grupo para enfrentar otros actores, los presentan como víctimas de una situación y no como potencia creadora o realizadora de una nueva forma de conviviry de resolver el conflicto. Tal vez se mira desde el ángulo en que la no violencia aparece como signo de debilidad y fragilidad, ${ }^{24}$ a lo cual se suma el hecho de que esa debilidad y fragilidad necesita ser protegida $y$ resguardada de la violencia que la rodea.

Algunos ejemplos de escritos que resaltan aspectos de la guerra y de la violencia, que en muchos casos inician sus primeros párrafos, leídos normalmente por la gente común, con los hechos violentos, o que presentan a la población como víctima, sin empezar por resaltar su acción autónoma pacifista. Sólo por mostrar a qué me refiero:

Por la Vida, la Pazy la Democracia. Llamamiento de todos los sectores de víctimas de crímenes contra la humanidad en Colombia.

http://gloriainesramirez1.blogspot.com/2008_02_01_ archive.html

Los rumores sobre la presencia de grupos paramilitares provenientes del Casanaréy del Dorado, y de paramilitares encubiertos con las tropas del Batallón 21 Vargas -que hace presencia en la zona-, los permanentes acosos contra la comunidad civil de vida y paz, Civipaz, y contra otros líderes de las comunidades de El Castillo, hacen prever un alto riesgo para la comunidad, como se demuestra en el atentado contra la vida del señor Isaías López.

http://www.dhcolombia.info/spip.php?article416

Mayor protección. Varias comunidades visitadas en las zonas más peligrosas subrayaron la importancia que proporciona la presencia del PMA en términos de aumentar la protección física. Esto fue especialmente el caso de dos "comunidades en situación de riesgo", Tangui en el Chocó y "Civipaz" en el Meta. Las mismas poblaciones contaron que cuando hay presencia del PMA hay menos posibilidades de que los actores armados 
escojan las comunidades como objetivo. Por lo menos en uno de los casos, la comunidad atribuyó a este efecto la misma importancia que la llegada de los alimentos. Jefes de agencias de Naciones Unidas al igual que varios donantes internacionales manifestaron tener la misma percepción.

Programa mundial de alimentos, La Evaluación de la OPSR Colombia 10366, http://documents.wfp.org/ stellent/groups/public/documents/reports/wfp154599. pdf

Después de que en el segundo semestre de 1996 y el primer semestre de 1997, fuerzas paramilitares realizaran dos masacres en la jurisdicción de San José de Apartadó, se intensificó el desplazamiento no voluntario de familias hacia otros territorios.

http://www.gfbv.it/3dossier/colombia/sanjose-es.html

En un informe de 57 páginas dedicado a las comunidades de paz en San José de Apartadó, San Francisco de Asís, Nuestra Señora del Carmen, Natividad de María y La Grande, en Antioquia y Chocó, al igual que al desplazamiento forzoso en ambos departamentos, Amnistía Internacional documenta en detalle la muerte de al menos 200 personas de estas comunidades desde que se establecieron en 1997, a manos de paramilitares, con el apoyo del Ejército, y de las guerrillas.

Sergio Gómez Maseri "Al abogar por comunidades de paz", Corresponsal de El Tiempo, Martes 20 de junio de 2000

Es más difícil encontrar escritos que sean informes, resúmenes de encuentros 0 entrevistas a miembros de las comunidades de paz, que empiecen resaltando su quehacer, su trabajo diario de construcción y reencuentro, su posición pacifista, su participación activa con su negación a convivir con agentes armados, su esfuerzo de organización e integración, su capacidad de solidarizarse con otros campesinos de la zona y del país. En su lugar, en algunos casos por un afán de defender a una población que vive una situación crítica, en otros por el placer de recrear la guerra que es más llamativa, sólo se muestran y resaltan las situaciones vividas, las muertes, las persecuciones, la presencia de grupos armados, la desatención del gobierno, entre otros aspectos.

Sin embargo, en muchos casos no se destaca la resistencia civil como estrategia pacifista, como condición de no-violencia, como una decisión y una actitud de la población, ni se muestra su proceso de organización e integración como expresión de un empoderamiento pacifista, de su potencia creadora de nuevas formas de interactuar y resolver el conflicto. Por el contrario, se resalta dicha resistencia como única salida al mundo de guerra al cual se vio enfrentada la población, como condición externa a ella, como consecuencia de lo mucho que los grupos armados han hecho y hacen frente a ella.

Por eso hay que enfatizar que: "No se trata de renunciar a la política como opción colectiva, sino de renunciar a la violencia como medio de hacer política". ${ }^{25}$

Se trata de entender la no-violencia como un método de intervención en conflicto con la idea de reducir hasta su nivel máximo la presencia y/o el uso de la violencia; pero no se queda ahí, ya que es también una forma de lucha no armada y no cruenta contra las diversas expresiones de las injusticias, por lo mismo apuesta a la confección de una ciencia política menos violenta, entendida como disciplina que libera a la humanidad de la violencia. A nivel personal la no violencia implica encontrar un sentido interno y profundo a la vida, a lo que hacemos, a cómo y por qué lo hacemos, implica hacer un viaje de introspección y búsqueda personal, así como cambiar la concepción del ser humano para verlo y entenderlo abierto a las transformaciones, en cierto sentido imperfecto y con conciencia moral. ${ }^{26}$ 
Es decir, salirse del marco de la relación amigoenemigo, que sólo percibe contrincantes, que juzga y condena el no estar de acuerdo o en posición de apoyo frente al que ejerce el poder. En esa medida, no se puede ser neutro o imparcial, no se puede estar en desacuerdo con ambos, hay que tomar partido, en la posibilidad de crear nuevas visiones, nuevas miradas y nuevas formas de actuar, que no impliquen la eliminación del otro, sino por el contrario la autoafirmación autónoma de la vida, que traiga convivencia pacífica y reconstrucción del tejido social. Debe asumirse como Martínez Guzmán que la paz, "además de ser condición de posibilidad de toda acción humana sea también meta a alcanzar indefinidamente, siempre en proceso de paces imperfectas".27

Pero ahora me interesa mostrar algunos párrafos que indican aspectos que interesan a la pazy al empoderamiento pacifista de estas comunidades, o lo que llamaríamos ejemplos a utilizar para mostrar el empoderamiento pacifista de las comunidades, que muchas veces quedan escritos en sus diarios o lo expresan en entrevistas realizadas a sus miembros, pero que, como se indicó en párrafos anteriores, no siempre resaltan quienes presentan el tema:

Continúa la siembra, semillas de memoria, semillas de pan coger, semillas de organización, semillas de esperanza. ${ }^{28}$

"Tuvimos mucho miedo cuando hace un año nos enteramos de lo que pasó en Apartadó, pero aún así queremos seguir organizados y continuar con nuestra zona humanitaria en la que no queremos que ningún grupo armado intervenga", sostuvo una mujer que también es vocera de la Comunidad Civil Vida y Paz Civipaz. $^{29}$

Desde entonces, cada viaje a Puerto Esperanza es informado oficialmente a la Vicepresidencia, la cancillería, el Ministerio del Interior y de Justicia, la Procuraduría, la Defensoría del Pueblo y la Fiscalía General.

Esperanza es el nombre del caserío pero también lo que mejor explica el arrojo de estos campesinos.

http://ipsnoticias.net/nota.asp?idnews=36970

Al cabo de uno meses los que estaban en Villavicencio empezaron a organizarse pensando en la posibilidad de regresar a sus tierras. Crearon La Comunidad de Vida y Paz del municipio de El Castillo - Civipaz, todavía estaban desplazados, pero ya buscaban los apoyos para el retorno, si las condiciones de seguridad se daban. ....

Pero en marzo de 2005, sin esperar el apoyo estatal, y tras varios meses de acondicionar una fina cercana a Puerto Esperanza, algunas familias volvieron, como una Comunidad unida, pero recelosa de cualquiera de los actores armados, legales 0 ilegales.

El Castillo / Meta / Febrero 2007, Por Ismael Santaclara http://www.surimages.com/ reportajes/080210CIVIPZcastillo.htm

La Comunidad se encuentra ahora asentada en San Josesito de la Dignidad, un pedazo de tierra al lado de la carretera un kilómetro antes de llegar a San José. A la entrada hay unas palabras escritas en un rectángulo de lámina de metal en donde le avisan muy claramente a los visitantes lo que significa entrar a la Comunidad de Paz: no se permite el porte de armas; no se acepta la presencia de ningún actor armado; no se está de acuerdo con la injusticia y 'libremente' la comunidad participa en los trabajos comunitarios.

Como nos dice María Brígida y el Padre Giraldo, la Comunidad de Paz no es sólo una forma de sobrevivir entre una guerra que no les pertenece y de la que sin embargo son sus principales víctimas. La creación de la Comunidad es también la construcción de un "mundo diferente", en donde se proponen y exploran caminos de vida distintos a los que esta sociedad ofrece e impone, en donde las relaciones con la tierra y con las otras personas son sustentables y de respeto, pues "(...) la paz no se construye con las armas. La paz se construye

27. Martínez Guzmán, V. (2004): «Teorías de la guerra en el contexto político de comienzos del siglo XXI», en Murillo, l. (ed.) (2004): Filosofía práctica y persona humana, Servicio de Publicaciones Universidad Pontificia de Salamanca, Salamanca: Ediciones Diálogo Filosófico.

28. Diarios de la comunidad Civipaz, disponible en: http://209.85.135.104/search?q=cache:G_YSdW5yOawJ:es.geocities.com/cijpdever/ dv230.doc+\%22Zona+humanitaria\%22\&hl=es\&ct=clnk\&cd=1\&gl=es\&lr=lang_es

29. El Tiempo, reportaje "LLANO 7 DIAS", 27 de febrero de 2006, edición impresa 
con alternativas de vida. (...) yo creo que el llamado es que para construir la paz que no se construye con las armas, se construye sin las armas, y se construye desde el reconocimiento de que nadie es más que nadie. Desde ahí se puede construir la paz. La paz se construye desde el corazón.

Hugo Idárraga, Sábado 26 de enero de 2006 http:// www.polodemocratico.net/La-Comunidad-de-Paz-deSan-Jose

Seis encuentros en Colombia, uno en España y este en Estados Unidos han permito reconocer nuestras especificidades, compartir la identidad de los problemas, logrando vincular nuestras comunidades en campañas de información y sensibilización, en acciones de presión e incidencia política, en el diseño de escuelas populares y de universidades alternativas, en nuevas prácticas de protección de territorios y en la afirmación desde la memoria colectiva de la Verdad, Justicia y Reparación. Poco a poco hemos ido tejiendo la Red de Alternativas a la Impunidad y la Globalización para fortalecer el valor de las actuaciones políticas y los hermanamientos entre movimientos sociales y comunidades. Se ha ido tejiendo, conjuntamente, una mirada global de los problemas que atraviesan todos los países en el mundo.

Reconocemos necesidades de esclarecer con nuestra coherencia teórica y práctica, las sendas por las que tratamos de caminar sin protagonismos, pero queriendo constituirnos como sujetos dispuestos a articular nuestras tareas en las redes de movimientos sociales globales que apuestan por la construcción de este otro mundo posible que soñamos.

Reunidos en Chicago el 12 de Noviembre de 2006.

Encuentro internacional Comunidades en Resistencia: Globalización de la justicia, medio ambiente y territorio. Declaración final

http://www.gloobal.net/iepala/gloobal/fichas/ficha.ph p?id=2276\&entidad=Declaraciones

El proceso de resistencia civil en Colombia: La experiencia de las Zonas Humanitarias

Es este el contexto en el cual las Zonas Humanitarias aparecerán: surgirán como una estrategia de distinción y de protección en medio del conflicto armado. Pero aún más a fondo, permitirán a las comunidades agruparse, organizarse, y emprender sus proyectos de vida autónomos. Las Zonas Humanitarias son enclaves de resistencia civil en medio del conflicto armado que, apoyándose en el Derecho Humanitario Internacional tanto como en el acompañamiento nacional e internacional, constituyen una nueva estrategia ante el despliegue paramilitar y militar que se efectúa hoy en Colombia.

Proyecto acompañamiento solidaridad Colombia http://www.pasc.ca/spip.php?article157

A pesar del control poblacional, del bloqueo económico hombres, mujeres, jóvenes, niños y niñas, ancianos tomaron la decisión de seguir abriendo ese espacio de libertad. Fueron seis días de trabajo en la tierra, de soñar despiertos, de ver hacer realidad de a poco esos sueños, de encontrarse con los viejos amigos, los otros campesinos que resisten en su tierra.

http://es.geocities.com/cijpdever/dv230.doc

Los Alcaldes de Paz han sido informados por Kolkoderechos humanos por Colombia, acerca de la valiente lucha de varias comunidades campesinas en las áreas rurales de Colombia en defensa de los derechos humanos y de una coexistencia pacífica. Esto, en medio de un conflicto interno armado que lleva 40 años y que involucra a fuerzas armadas, grupos paramilitares y organizaciones guerrilleras.

Mensaje de los Alcaldes de Paz a las Comunidades de Paz de Colombia Agosto 12 de 2005

http://www.dhcolombia.info/spip.php?article232

Identificar estos sueños, sentimientos, deseos, expresiones, decisiones y acciones de la población que ha experimentado y sigue experimentando situaciones de conflicto, pero que se aferra a superarlas por vía noviolenta y exige respeto, abriendo puertas a nuevas miradas y formas de pensar.

Por ejemplo, pensar en la resistencia como nuevo rumbo, en el sentido dado por Oscar Useche, quien opina que:

Resistir es crear mundos nuevos en donde haya espacios inéditos para imaginarse formas de relación libres de 
poderes dominantes, y ello plantea el ejercicio de la desobediencia a toda forma de poder despótico, así como la necesidad de crear las condiciones para dar alas al impulso vital que permite liberar el cuerpo, el deseo y el pensamiento. ${ }^{30}$

O reconocer que si la experiencia propia es importante, también lo es la ajena, razón por la cual es absurdo desperdiciar la oportunidad de enriquecer el quehacer cotidiano, la práctica y la teoría misma, dejando en el olvido, lo que motiva e inquieta a actuar $^{31}$ sea a una persona, a un grupo o a una especie y sobre todo, lo que les pueden enseñar los procesos y las situaciones vividas, al compartir la experiencia como expresión de la potencia y el resultado de un apoderarse de su situación.

Por eso inquieta notar que hace poco más de un año, las noticias de los principales diarios del país sobre las comunidades de paz se refieren a los procesos, posibles condenas y resultados de las investigaciones sobre los actos violentos cometidos contra ellas, pero no mencionan qué están haciendo, qué progresos han tenido, cómo evalúan su experiencia, cómo siguen resistiendo, siguen empoderadas y sobre todo cómo ven su futuro. Puede que ya no sea noticia, pero estamos perdiendo una enseñanza de vida, un posible ejemplo para formarnos y seguir creciendo.

Por todo lo mencionado, se me ocurre asociar la idea de la Paz imperfecta ${ }^{32}$ con la imagen de una cuerda, no por su linealidad, sino por sus dos cabos, sus dos puntas, sus dos extremos interrelacionados; por un lado, es una herramienta intelectual para pensar y entender la paz, y por el otro, un ejercicio praxeológico para hacer la paz. No se sabe dónde empieza uno, ni dónde termina el otro, solo se sabe que están unidos. Esto abre la puerta para que cada persona pueda relacionarse con el tema, a partir de donde se sienta más fuerte, desde su experiencia y vivencia, con lo que piense y sienta que es, o puede ser un proceso de construcción de paz propio o ajeno, para que empiece a ligarse con el otro, sin sentir que está en un terreno diferente, a pesar de estar trabajando ambos por lograr mejores condiciones de vida, bienestar y armonía, entendiendo que ese "ambos" puede y debe ser para muchos, que por ser o formar parte de un proceso inacabado está en una permanente transición en la cual aún se puede participar desde cualquiera de las dos puntas o extremos mencionados.

\section{FUENTES DE INFORMACIONTEXTOS CONSULTADOS}

Arias, G. (1995) Proyecto político de la noviolencia, Madrid: Nueva utopía.

Barreix, J. y Castillejos, S. (2003) Metodología y método en trabajo social, Buenos Aires: Editorial Espacio.

Galtung, J. (1995) Investigaciones teóricas: sociedad y cultura contemporánea,

Madrid:Tecnos.

Juliao, C. G. (2007) Educación Social: el Minuto de Dios. Una experiencia y un modelo, Bogotá: Uniminuto.

Juliao, C. S. (2006) Anotaciones a la sistematización de la práctica profesional como recuperación de experiencias de trabajo social", Revista Polisemia No. 2, Uniminuto.

León, R. Buscar paz: una buena práctica, en El Mundo Edición de septiembre 13 de 2006. Lopez, M. (2006) Política sin violencia: la noviolencia como humanización de la política, Bogota: Uniminuto.

30. Useche, O. (Junio 20 de 2003) "La potencia creativa de la resistencia a la guerra", Ponencia presentada al Foro Social Mundial Temático, Cartagena de Indias.

31. Juliao, C. S. (2006 - julio a diciembre) "Anotaciones a la sistematización de la práctica profesional como recuperación de experiencias de trabajo social" Revista Polisemia No. 2, Uniminuto.

32. No en tanto categoría analítica, en el sentido de Muñozy Molina, sino como móvil explícito de nuestro actuar e interés por saber y conocer frente al tema. 
Martínez, V. (2000) "Saber hacer las Paces. Epistemologías de los estudios para la paz" en Convergencia, Revista de Ciencias sociales, Universidad Autónoma de México.

Martínez, V. (2006) "Teorías de la guerra en el contexto político de comienzos del siglo XXl», en Murillo, I. (ed.) (2004): Filosofía práctica y persona humana, Servicio de Publicaciones Universidad Pontificia de Salamanca. Salamanca: Ediciones Diálogo Filosófico.

Martínez, V. (¿año?) Políticas para la Diversidad: Hospitalidad contra Extranjería, Universitat Jaume I, Centro Internacional Bancaja para la Paz y el Desarrollo.

Moran, E. (1999) "Los siete saberes necesarios para la educación del futuro", Molina y Muñoz (2004) (eds), "Manual de Paz y Conflictos", Universidad de Granada, Granada: Colección Eirene.

Muñoz y Molina, "Una paz compleja, conflictiva e inacabada", Instituto de Paz y Conflictos, Universidad de Granada. Ponencia aun no publicada del Seminario Una Paz Compleja y conflictiva.

Muñoz-Herrera-Molina-Sánchez. "Investigación de la paz y los derechos humanos desde Andalucía", Granada: Colección Monográfica Eirene Núm. 20.

Muñoz, Francisco. (2007) "La paz imperfecta ante un universo en conflicto" apartes 5.2 y 5.3 Granada: Universidad de Granada

Sudarsky, J. (2002) El capital social en Colombia, Bogotá.

Useche, O. (Junio 20 del 2003) "La potencia creativa de la resistencia a la guerra", Ponencia presentada al Foro Social Mundial Temático, Cartagena de Indias.

\section{PAGINAS DE INTERNET MENCIONADAS:}

http://www.colombiacivica.org.co

http://indh.pnud.org.co/articulos. plx?t=informePrensa

http://209.85.135.104/search?q=cache:G_ YSdW5y0awJ:es.geocities.com/cijpdever/ dv230.doc+\%22Zona+humanitaria\%22\&hl= es\&ct=clnk\&cd=1\&gl=es\&|r=lang_es

http:www.dhcolombia.info/spip. php?article416

http://gloriainesramirez1.blogspot. com/2008_02_01_archive.html

http://documents.wfp.org/stellent/groups/ public/documents/reports/wfp154599.pdf

http://209.85.135.104/search?q=cache:G_ YSdW5y0awJ:es.geocities.com/cijpdever/ dv230.doc+\%22Zona+humanitaria\%22\&hl= es\&ct=clnk\&cd=1\&gl=es\&|r=lang_es

http://ipsnoticias.net/nota. asp?idnews $=36970$

h t t p:/ / w w w.surimages.com / reportajes/080210CIVIPZcastillo.htm http://es.geocities.com/cijpdever/dv230. doc

http://www.gloobal.net/iepala/gloobal/ fichas/ficha.php?id=2276\&entidad=Declara ciones

http://www.pasc.ca/spip.php?article157

http://www.polodemocratico.net/LaComunidad-de-Paz-de-San-Jose 


\section{Anexo para la reflexión sobre el giro praxeológico - para incentivar nuevas búsquedas.}

\section{Ejemplos de acción no-violenta:}

\section{- Creación de comunidades civiles en zonas de conflicto armado:}

Comunidad Civil de Vida y Paz, Civipaz, en el departamento del Meta al oriente del país, que después del desplazamiento forzado de las familias, decidió restablecerse en zonas cercanas a su habitad inicial y a partir de la cooperación entre sus miembros y de un largo proceso de no enfrentamiento con los grupos armados se dio a conocer y delimitó una zona humanitaria ${ }^{33}$

Tomo este caso, en el marco de la zonas humanitarias en Colombia, para mostrarla como situación de autodeterminación de una población que no puede ser considerada víctima por ser frágil, sino como potencia por haber escogido una forma alternativa para vivir a pesar de encontrarse en medio del conflicto entre otros agentes, como ellos mismos lo declaran, por lo tanto merece ser distinguido como situación dentro del tema de empoderamiento pacifista y de no-violencia.

Esta comunidad de 17 familias de campesinos desplazados de la región del Alto Ariari, decidió como ejemplo de buena práctica ${ }^{34}$ organizarse en un proceso civil bajo el nombre de Comunidad Civil de Vida y Paz, y se estableció en el Corregimiento de Medellín del Ariari, del municipio de El Castillo, departamento del Meta, reconstruyendo espacios de habitación y delimitación.

\section{- Manifestaciones pacíficas}

\section{Cacerolazo en el Meta: (enero de 2001)}

Un "cacerolazo" y un apagón voluntario fueron las formas utilizadas por los habitantes del sureño departamento del Meta y de Bogotá para expresar su rechazo a la escalada de violencia desatada por la guerrilla en las últimas semanas. El repudio está dirigido a las acciones de las Fuerzas Armadas Revolucionarias de Colombia (FARC), que provocaron el racionamiento eléctrico en el departamento del Meta. "Con esta manifestación... estamos exigiendo respeto y hechos de paz inmediatos y reales", puntualizó el gobernador del Meta, Luís Carlos Torres.

(http://www.esmas.com/noticierostelevisa/internacionales/215683.html)

33. Romero Sabogal, Y. (Julio de 2006). Tesis de grado en la carrera de Trabajo Social, Facultad de Ciencias Humanas y Sociales, Uniminuto. "lugar delimitado y determinado, donde se exige la no presencia de ningún actor armado, fuerza pública, paramilitares y guerrilla, puesto que estos lugares tienen como objetivo claro el ser refugios cuando se den confrontaciones entre los actores armados. De igual manera se exige que estos espacios no puedan ser bombardeados, ni atacados, estos lugares se delimitan con una cerca de alambre, yen sus esquinas se visibiliza el lugar, por medio de vallas", cita del Encuentro de Comunidades en Resistencia, San José de Apartadó, pp. 6 - 7 (septiembre 2005).

34. Buena práctica en el sentido del PNUD como aquella "acción o ejemplo concreto que ayuda a disminuir los efectos del conflicto y sentar las bases para una paz sólida y estable" citado por Ricardo León Cruz El Mundo - Septiembre 13 de 2006 en su articulo "Buscar paz : una buena practica", $h$ ttp://indh.pnud.org.co/articulos.plx?t=informePrensa 
Marcha por la paz en el Valle: (diciembre de 2006)

Así mismo, los palmiranos rechazaron las acciones que atentan contra la vida y "aunque sabemos que marchar no evitará esos hechos, sí es una forma de crear conciencia entre quienes hacen el mal", dijo el ama de casa Marina Caicedo.

Lidia Escobar, empleada:"Marchamos porque queremos un cambio para la sociedad. Ya es hora de que respiremos en una atmósfera de paz y tranquilidad quienes habitamos el Valle del Cauca".

Nelson Marín, trabajador: "Hay que tratar de que los gobiernos logren conseguir la paz en todos los sentidos, pues generar bienestar social, salud y más viviendas es hacer la paz".

Rosiber Talaga, ama de casa:"Pedimos por la paz de todo el Valle, especialmente, la paz para los niños. Y aunque mucha gente crea que marchar no sirve, eso logra llamar la atención de los violentos y cambiar la mentalidad". (http://www.elpais.com.co/historico/dic062006/REG/marcha.html)

\section{Convocatoria a bloqueo por no uso de servicios}

El jueves 17 de abril se llevará a cabo una jornada de No al Transmilenio, convocatoria que fue hecha por la red social de Facebook. El día sin Transmilenio es un día de protesta pacífica donde los usuarios de este sistema rechazaran el mal servicio por el alto precio que se paga.

Ya que muchas veces los usuarios se han quejado, han hecho bloqueos y las directivas distritales y de Transmilenio no han tenido en cuenta estas protestas.

(http://www.radiosantafe.com/2008/04/14/dia-de-no-transmilenio-17-de-abril/) 